\title{
TRICHOSCOPIC STUDY OF NON-SCARRING ALOPECIA OF THE SCALP
}

\author{
Mohamed Salahudeen'1, Roshni Menon², Brinda David ${ }^{3}$ \\ ${ }_{1}^{1}$ Postgraduate Student, Department of Dermatology, Venereology \& Leprosy, Sri Venkateshwaraa Medical College Hospital \& Research \\ Centre. \\ 2Professor, Department of Dermatology, Venereology \& Leprosy, Sri Venkateshwaraa Medical College Hospital \& Research Centre. \\ ${ }^{3}$ Assistant Professor, Department of Dermatology, Venereology \& Leprosy, Sri Venkateshwaraa Medical College Hospital \& Research \\ Centre.
}

ABSTRACT

\section{BACKGROUND}

Trichoscopy is a tool used in the diagnosis of alopecia, but its utility has not been completely assessed.

The objective is to study the dermoscopy findings of different types of non-scarring alopecia of the scalp.

\section{MATERIALS AND METHODS}

A cross-sectional study was performed in patients with non-scarring alopecia. After clinical assessment and relevant investigations, trichoscopy was performed using a non-polarised trichoscope $(\times 10)$. The utility of trichoscopy in difficult cases of alopecia was assessed statistically.

\section{RESULTS}

In our study, out of 200 cases, 92 cases (46\%) were of androgenetic alopecia, 70 cases (35\%) were alopecia areata, 36 cases (18\%) were telogen effluvium and 2 cases had both androgenetic alopecia and alopecia areata. Hair diameter diversity was observed in all cases of androgenetic alopecia with peripilar sign being the most frequent findings. In alopecia areata, the most common findings were black dots (51.4\%) followed by broken hair (31.4\%) and yellow dots (30.0\%). In telogen effluvium, one follicular hair unit and empty hair follicles were seen in all cases.

\section{CONCLUSION}

Trichoscopy is useful in the differential diagnosis of alopecia. Among the various trichoscopic findings, those of diagnostic value were identified.

\section{KEYWORDS}

Alopecia, Non-scarring, Trichoscopy.

HOW TO CITE THIS ARTICLE: Salahudeen M, Menon R, David B. Trichoscopic study of non-scarring alopecia of the scalp. J. Evolution Med. Dent. Sci. 2017;6(68):4894-4898, DOI: 10.14260/Jemds/2017/1061

\begin{abstract}
BACKGROUND
In humans, hair is an important indicator of individual characteristics such as self-image, identity, ethnicity and health, among other attributes. Hence, diseases that result in hair loss lead to low self-esteem and impaired psychosocial interactions. Patients with hair loss are usually very distressed and often feel they are not properly examined. Examination with a dermoscope can reassure the patient that they have received a thorough scalp examination and helps

hair loss disorders (e.g. simple clinical inspection, pull test, and biopsy) vary in specificity, interpretation, and invasiveness. Dermoscopy is a new and valuable tool in this arsenal. Scalp dermoscopy does not only facilitate diagnosis of hair disorders but it can also give clues about disease stage and progression. The number of studies carried out on dermoscopy of alopecia in India is limited. This study is to evaluate the trichoscopic features of non-scarring alopecia in a tertiary care hospital in South India.
\end{abstract} the clinician to distinguish between different clinical diagnosis. Dermoscopy (Also known as dermoscopy, epiluminescence microscopy, amplified surface microscopy, and surface diascopy) is a non-invasive examination technique of evaluation of the colours and microstructures of the epidermis, dermoepidermal junction, and papillary dermis not visible to the naked eye; thereby enhancing the diagnostic accuracy. The standard methods used to diagnose

Financial or Other, Competing Interest: None.

Submission 10-04-2017, Peer Review 03-05-2017,

Acceptance 10-05-2017, Published 24-08-2017.

Corresponding Author:

Dr. Mohamed Salahudeen,

Department of Dermatology, Venereology \& Leprosy,

Sri Venkateshwaraa Medical College Hospital \&

Research Centre, Ariyur, Puducherry-605102.

E-mail: sala_89@hotmail.com

DOI: $10.14260 /$ jemds $/ 2017 / 1061$

\section{MATERIALS AND METHODS}

A cross-sectional study was done in the Dermatology OPD of Sri Venkateshwaraa Medical College and Hospital from October 2014 to May 2016. About 200 consenting patients who fulfilled the inclusion criteria were chosen for the study. The demographic characteristics were included in the study and the clinical profile of the patient such as haematological investigation were assessed. KOH mount, skin biopsy were done if needed after getting informed consent from the patients. Trichoscopy was performed with a non-polarised Heine delta 20 dermatoscope (10× magnification) using liquid paraffin as the contact medium. The centre and periphery of the alopecic patch were examined by trichoscopy and photographs taken using a 23 MP Sony Z5 camera (3264 × 2448 pixels, autofocus, LED flash) without and with $4 \times$ magnification. 


\section{Statistical Analysis}

Descriptive statistics- mean and standard deviation for quantitative variables was estimated. Proportion (\%) with 95\% confidence interval was be estimated for qualitative variables. The data was analysed using SPSS (Version 23).

\section{RESULTS}

In our study, out of 200 cases, 92 cases (46\%) were of androgenetic alopecia, 70 cases (35\%) were alopecia areata, 36 cases $(18 \%)$ were telogen effluvium and 2 cases had both androgenetic alopecia and alopecia areata. Hair diameter diversity was observed in all cases of androgenetic alopecia with peripilar sign being the most frequent findings. In alopecia areata, the most common findings were black dots $(51.4 \%)$ followed by broken hair (31.4\%) and yellow dots $(30.0 \%)$. In telogen effluvium, one follicular hair unit and empty hair follicles were seen in all cases.

\begin{tabular}{|c|c|c|}
\hline \multirow{2}{*}{ Trichoscopic Findings } & \multicolumn{2}{|c|}{ Total (n=92) } \\
\cline { 2 - 3 } & $\mathbf{N}$ & $\mathbf{\%}$ \\
\hline Hair diameter diversity & 92 & 100 \\
\hline Peripilar sign & 77 & 83.7 \\
\hline Yellow dots & 49 & 53.3 \\
\hline White dots & 37 & 40.2 \\
\hline Honeycomb pigment pattern & 23 & 25 \\
\hline Table 1. Trichoscopic Findings of Androgenetic Alopecia \\
\hline
\end{tabular}

\begin{tabular}{|c|c|c|}
\hline \multirow{2}{*}{ Trichoscopic Findings } & \multicolumn{2}{|c|}{ Total (n=70) } \\
\cline { 2 - 3 } & $\mathbf{N}$ & $\mathbf{\%}$ \\
\hline Black dots & 36 & 51.4 \\
\hline Yellow dots & 21 & 30.0 \\
\hline Broken hair & 22 & 31.4 \\
\hline Exclamatory mark hair & 13 & 18.6 \\
\hline Short vellus hair & 14 & 20.0 \\
\hline Re-growing hair & 2 & 2.9 \\
\hline Table 2. Trichoscopic Findings of Alopecia Areata \\
\hline
\end{tabular}

\begin{tabular}{|c|c|c|}
\hline \multirow{2}{*}{ Trichoscopic Findings } & \multicolumn{2}{|c|}{ Total (n=36) } \\
\cline { 2 - 3 } & $\mathbf{N}$ & $\mathbf{\%}$ \\
\hline One follicular hair unit & 36 & 100 \\
\hline Empty hair follicle & 36 & 100 \\
\hline Small white dots & 16 & 44.4 \\
\hline Table 3. Trichoscopic findings of Telogen effluvium \\
\hline
\end{tabular}

\begin{tabular}{|c|c|c|c|c|c|c|c|}
\hline $\begin{array}{c}\text { Dermoscopic } \\
\text { Feature }\end{array}$ & \multicolumn{2}{|c|}{ AA } & \multicolumn{2}{|c|}{ AGA } & \multicolumn{2}{|c|}{ TE } & \multirow{2}{*}{ p value } \\
\cline { 2 - 8 } & $\mathbf{\%}$ & $\mathbf{N}$ & $\mathbf{\%}$ & $\mathbf{N}$ & $\mathbf{\%}$ & \\
\hline Black dots & 36 & 18.0 & 0 & 0 & 0 & 0 & $<0.0001^{*}$ \\
\hline Yellow dots & 49 & 24.5 & 21 & 10.5 & 0 & 0 & $<0.0001^{*}$ \\
\hline White dots & 0 & 0 & 37 & 18.5 & 16 & 8.0 & $<0.0001^{*}$ \\
\hline Tapering hair & 13 & 6.5 & 0 & 0 & 0 & 0 & $<0.0001^{*}$ \\
\hline Broken hair & 22 & 11.0 & 0 & 0 & 0 & 0 & $<0.0001^{*}$ \\
\hline Short vellus hair & 14 & 7.0 & 0 & 0 & 0 & 0 & $<0.0001^{*}$ \\
\hline Coudability sign & 0 & 0 & 0 & 0 & 0 & 0 & NA \\
\hline HCPP & 0 & 0 & 23 & 11.5 & 0 & 0 & $<0.0001^{*}$ \\
\hline HDD & 0 & 0 & 92 & 46.0 & 0 & 0 & $<0.0001^{*}$ \\
\hline PPS & 0 & 0 & 77 & 38.5 & 0 & 0 & $<0.0001^{*}$ \\
\hline Scales & 11 & 5.5 & 21 & 10.5 & 12 & 6.0 & 0.1161 \\
\hline ARL & 0 & 0 & 20 & 10.0 & 0 & 0 & $<0.0001^{*}$ \\
\hline Empty follicles & 0 & 0 & 0 & 0 & 36 & 18.0 & $<0.0001^{*}$ \\
\hline $\begin{array}{c}\text { Single hair } \\
\text { follicular unit }\end{array}$ & 0 & 0 & 5 & 2.5 & 36 & 18.0 & $<0.0001^{*}$ \\
\hline $\begin{array}{c}\text { Multi hair } \\
\text { follicular unit }\end{array}$ & 70 & 35.0 & 87 & 43.5 & 36 & 18.0 & $0.0521^{*}$ \\
\hline Table 4. Dermoscopic Feature of Non-scarring Alopecia \\
\hline
\end{tabular}

$* \mathrm{p}<0.05$ is consider as a significant level.

\begin{tabular}{|c|c|c|c|c|c|c|c|c|}
\hline $\begin{array}{c}\text { Trichoscopic } \\
\text { Findings }\end{array}$ & $\begin{array}{c}\text { Present Study } \\
(\mathbf{n = 9 2 )}\end{array}$ & $\mathbf{\%}$ & $\begin{array}{c}\text { Kibar et al } \\
(\mathbf{n = 2 0 6})\end{array}$ & $\mathbf{\%}$ & $\begin{array}{c}\text { Inui et al } \\
(\mathbf{n = 6 0})\end{array}$ & $\begin{array}{c}\text { Ruiming } \\
\text { et al (n=950) }\end{array}$ & \% \\
\hline Hair diversity & 92 & 100 & 206 & 100 & 60 & 100 & 950 & 100 \\
\hline Peripilar sign & 36 & 51.4 & 63 & 84 & 35 & 66 & 419 & 44.1 \\
\hline Yellow dots & 14 & 20.0 & 51 & 68 & 14 & 23.3 & 151 & 20.9 \\
\hline White dots & 21 & 30.0 & 43 & 57.3 & 0 & 0 & 249 & 26.2 \\
\hline $\begin{array}{c}\text { Honeycomb } \\
\text { pigment pattern }\end{array}$ & 22 & 31.4 & 28 & 37.3 & 0 & 0 & 310 & 32.6 \\
\hline \multicolumn{7}{|l}{ Table 5. Comparison of Trichoscopic Findings in AGA with other Studies } \\
\hline
\end{tabular}

\begin{tabular}{|c|c|c|c|c|c|c|c|c|}
\hline $\begin{array}{l}\text { Trichoscopic } \\
\text { Findings }\end{array}$ & $\begin{array}{l}\text { Present Study } \\
\quad(n=70)\end{array}$ & $\%$ & $\begin{array}{c}\text { Hedge et al } \\
(n=75)\end{array}$ & $\%$ & $\begin{array}{l}\text { Inui et al } \\
(n=300)\end{array}$ & $\%$ & $\begin{array}{c}\text { Mane et al } \\
(n=66)\end{array}$ & $\%$ \\
\hline Tapering hair & 13 & 18.6 & 14 & 18.67 & 95 & 31.7 & 8 & 12.1 \\
\hline Black dot & 36 & 51.4 & 63 & 84 & 133 & 44.3 & 44 & 67.7 \\
\hline Vellus hair & 14 & 20.0 & 51 & 68 & 218 & 72.7 & 27 & 40 \\
\hline Yellow dot & 21 & 30.0 & 43 & 57.3 & 191 & 63.7 & 54 & 81.8 \\
\hline Broken hair & 22 & 31.4 & 28 & 37.3 & 137 & 45.7 & 36 & 55.4 \\
\hline
\end{tabular}




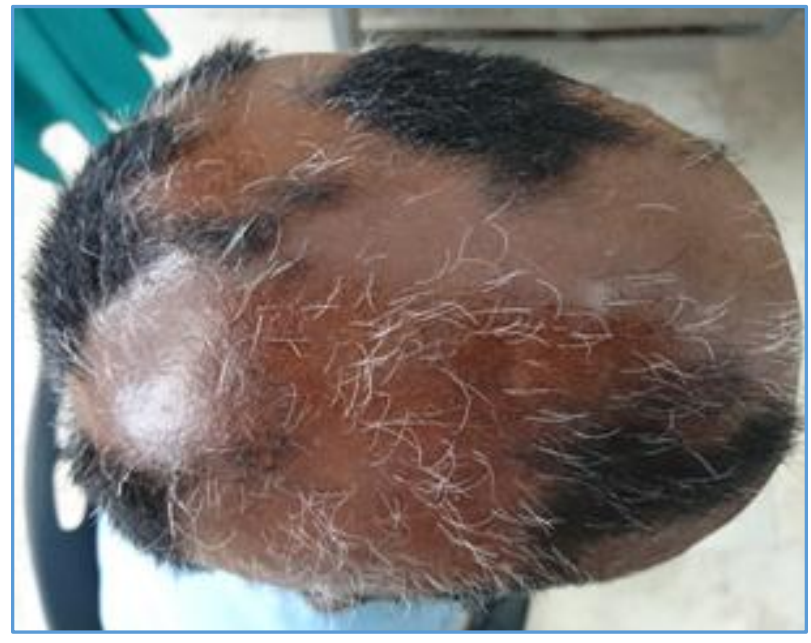

Figure 1. Showing Multiple Patchy Type of Alopecia Areata

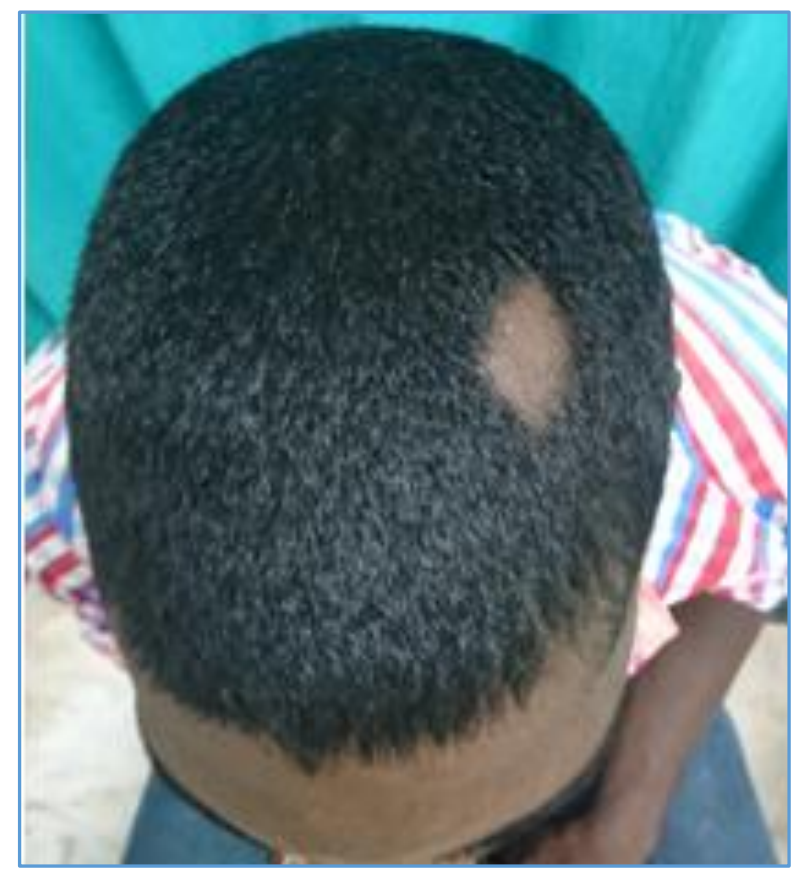

Figure 2. Showing Single Patchy Alopecia Areata over the left Parietal Area of the Scalp

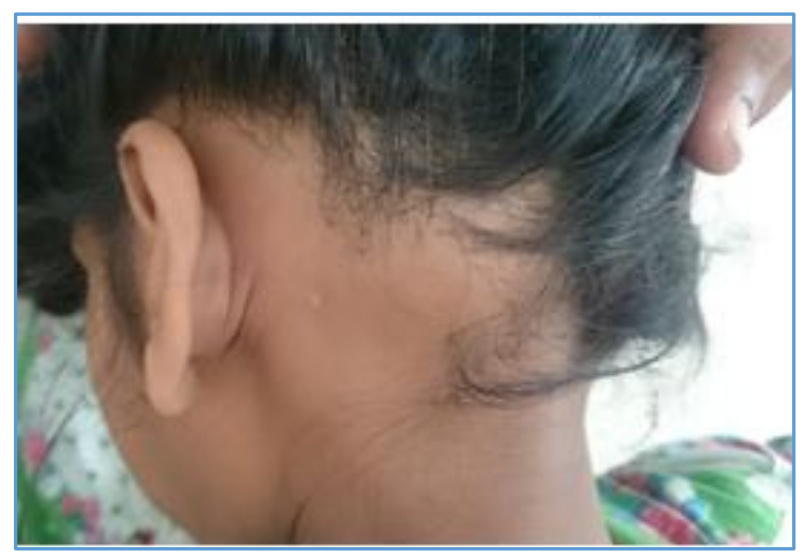

Figure 3. Showing Ophiasis type of Alopecia Areata

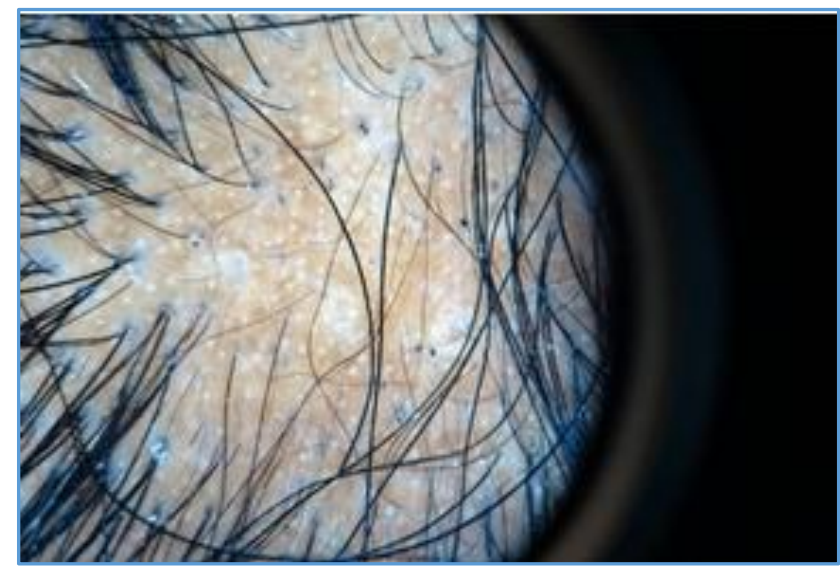

Figure 4. Showing Black Dots in $A A$

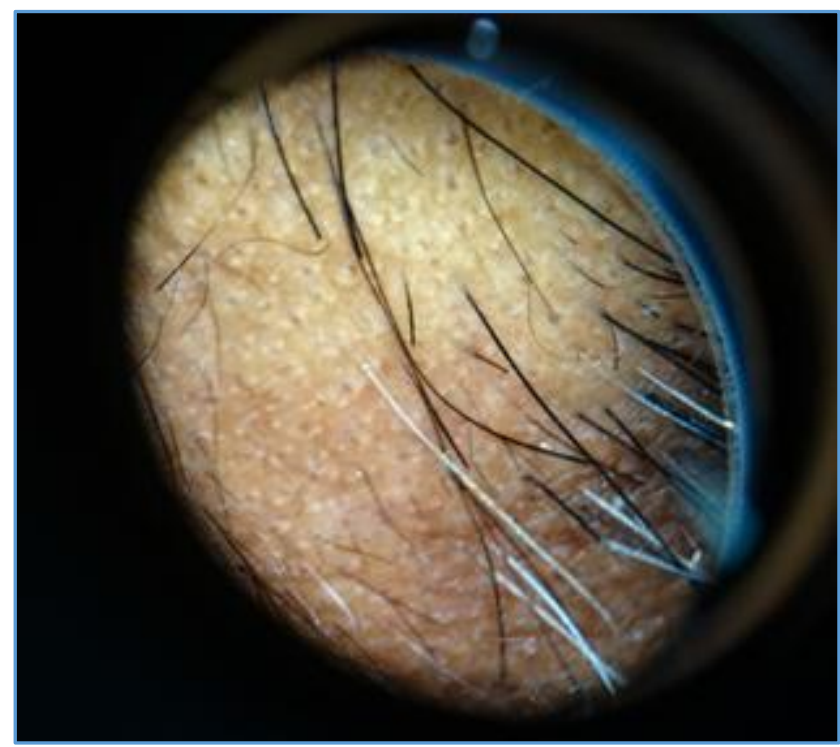

Figure 5. Showing Tapering Hair in $A A$

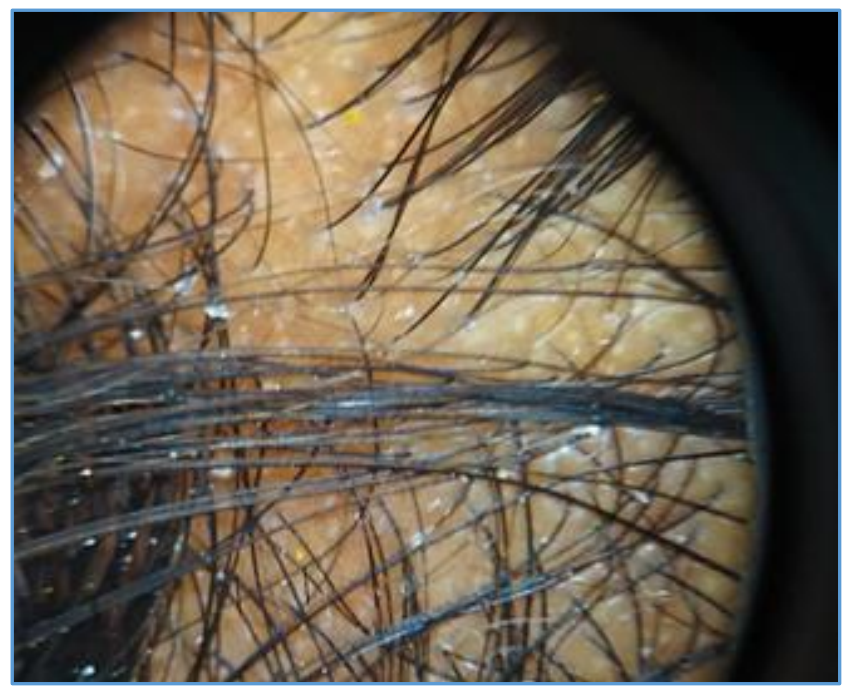

Figure 6. Showing Yellow Dots in $A A$ 


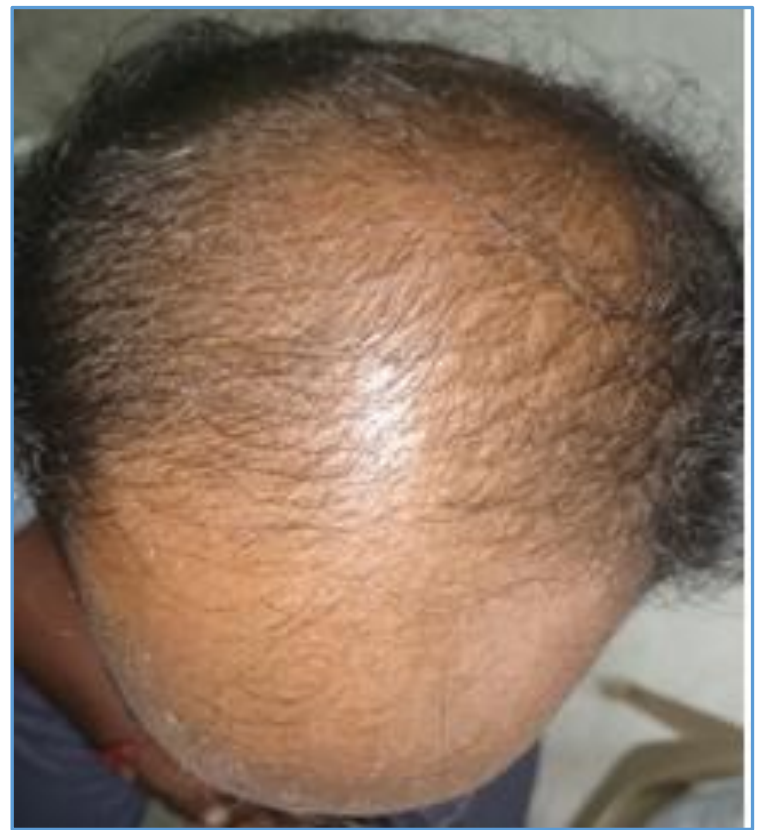

Figure 7. Showing AGA Hair loss over Vertex and Frontotemporal Recession (Grade V)

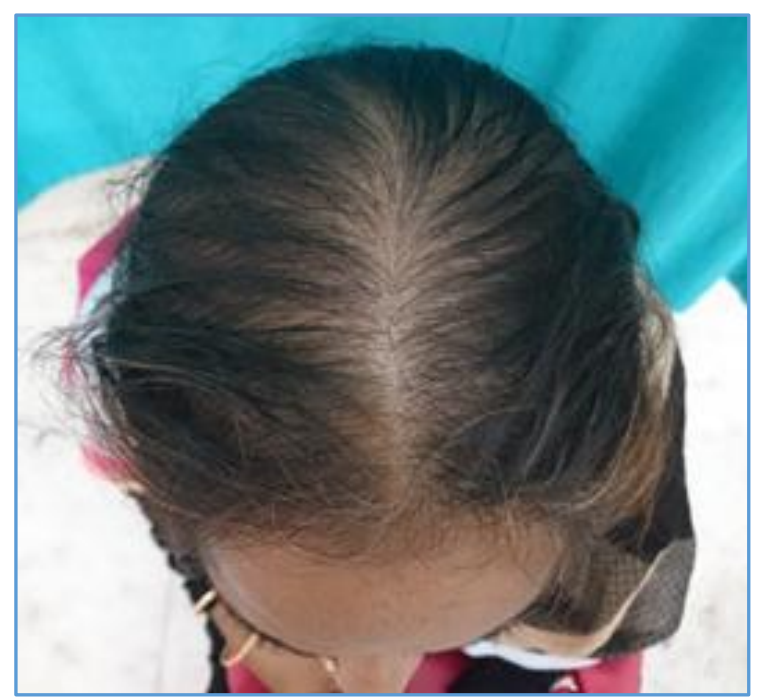

Figure 8. Showing Grade II Female Pattern Hair loss

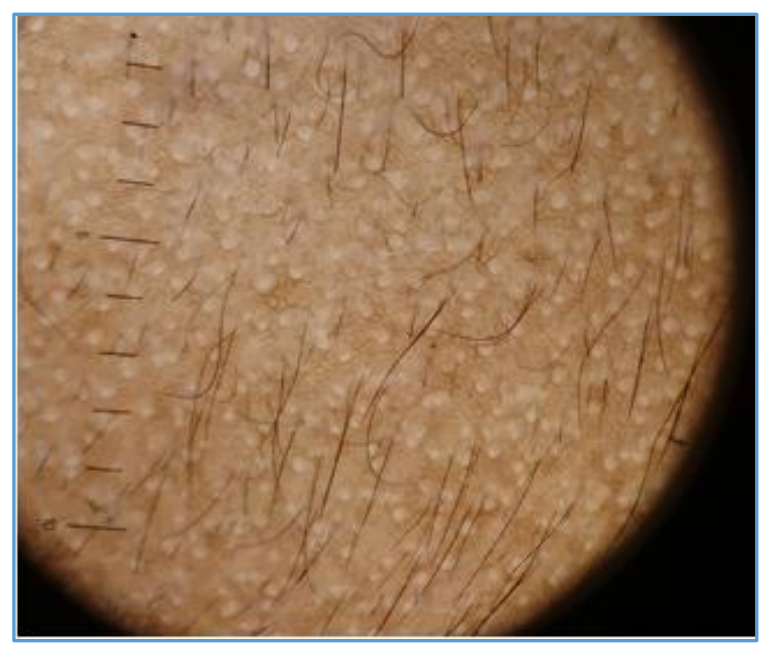

Figure 9. Showing Short Vellus Hair with Honeycomb Pigment Pattern with White dots in AGA

\section{DISCUSSION}

Hair loss is a frequent complaint, but it is a challenging task for dermatologists as therapeutic and diagnostic methods are rare. Dermoscopy in recent years has been established as an indispensable tool in the diagnosis and followup of hair disorders.

In our study comprising of 200 patients, 116 (58) were males and 84 (42) were females, a male preponderance was noted in this study. The mean age in this present study is 25.36 years (SD 7.23) among the types of non-scarring alopecia, 92 (46\%) cases were androgenetic alopecia, 70 (35\%) cases were alopecia areata, $36(18 \%)$ cases were telogen effluvium and 2 cases had both features of androgenetic alopecia and alopecia areata.

\section{Androgenetic Alopecia}

AGA is the most common form of hair loss both in men and women. In our study, out of 200 patients, 92 (46\%) cases were AGA of which $76 \%$ cases were male and $31.4 \%$ cases were female with a mean duration of 4.22 years. In our study, males were commonly affected than females with a male: female ratio of 2:1.

More than 20\% Hair diameter diversity (HDD) has been reported to be an early sign of AGA. ${ }^{1}$ In our study, HDD was seen in all the patients which is similar to the study conducted by Ruiming et $\mathrm{al}^{2}$ Inui et $\mathrm{al}^{3}$ and Kibar et al. ${ }^{4}$ Peripilar sign (PPS) is characterised by a brown halo around the hair shaft. This sign is linked to superficial perifollicular infiltrates composed mainly of lymphocytes. ${ }^{5}$ In our study, PPS was seen in $51.4 \%$ cases. Yellow dots (YD) in AGA are thought to be due to the result of sebaceous hypertrophy and lagooning in glands as a result of end organ hypersensitivity. ${ }^{6}$ In our study, YD were found to be correlated with the study done by Inui et al $(23.3 \%)$ and Ruiming et al $(20.9 \%)$. White dots (WD) have been found corresponding to the empty hair follicle ostia or to the epidermal portion of eccrine sweat ducts by histopathology. In our study, WD was seen in $30.0 \%$ cases which was found to be correlated with the study done by Ruiming et al (26.2\%). According to Ross et al, 7 honeycomb pigment pattern (HCPP) was related to chronic sun exposure. In our study, HCPP (31.4\%) was found to be comparable with the studies conducted by Kibar et al (37.3\%) and Ruiming et al (32.6\%).

\section{Alopecia Areata}

AA is a common condition characterised by patchy loss of hair without atrophy. ${ }^{8}$ The sex incidence is probably equal. ${ }^{9}$ In this study, 70 (35\%) patients had AA, with a mean duration of 3.51 months. The male: female ratio in our study was 2:1.

According to Ross et al, ${ }^{7}$ YD are considered to be the most sensitive dermoscopic feature of AA which represents distension of affected follicular infundibulum with keratinous material and sebum. The incidence of YD in our study was $30.0 \%$ which was found to be less compared to other studies. This could be attributed to the yellowish skin colour of Asian patients which makes it difficult to perceive yellow colour in dermoscopy. Black dots (BD) provide sensitive marker for disease activity which are remnants of exclamation mark hairs or broken hairs. In our study, BD was seen in 51.4\%. Tapering hair (also known as exclamation mark hair) is commonly seen in AA. In our study, tapering hair was found 
to be comparable with Hegde et $\mathrm{al}^{10}(18.6 \%)$ and Inui et al ${ }^{11}$ $(31.7 \%)$. This may be attributed to variation in disease duration and severity. Broken hairs $(\mathrm{BH})$ which are considered to be dystrophic hairs produced by the least severely affected follicles in AA are clinical markers of disease activity and severity. Inui et al demonstrated BHs in $45.7 \%$ cases. BHs was seen in $55.4 \%$ cases in the study conducted by Mane et al. ${ }^{12}$ In our study, BHs were seen in $31.4 \%$ cases. Regrowing hairs were seen in $2.9 \%$ in our study as the remaining patients have not undergone any treatment in the past.

\section{Telogen Effluvium}

In our study, $36(18 \%)$ cases had telogen effluvium with a mean duration of 2.27 months. Out of 36 cases, history of stress was noted in $21(58.3 \%)$ cases and $3(8.3 \%)$ cases had a history of typhoid fever within six months prior to the onset of TE. On laboratory investigations, 15 (41.6\%) cases were found to have anaemia.

In our study, trichoscopic features observed were single follicular hair unit (100\%), empty hair follicles $(100 \%)$ and small white dots (44.4\%).

\section{Limitation}

The study cannot be considered as a true representation from population as our cases were not distributed evenly across the different age groups. $63 \%$ of the sample belonged to 21 30 years category. Representation of elderly and paediatric age group were less. So special conditions causing nonscarring alopecia in these two age groups could not be given adequate importance.

\section{CONCLUSION}

In our study, the role of trichoscopy helped us to reach a conclusive diagnosis in alopecia. We conclude that trichoscopy is a relevant investigation in patients with alopecia.

\section{REFERENCES}

[1] De Lacharriere O, Deloche C, Misciali C, et al. Hair diameter diversity: a clinical sign reflecting the follicle miniaturization. Arch Dermatol 2001;137(5):641-6.
[2] $\mathrm{Hu} \mathrm{R}, \mathrm{Xu} \mathrm{F}, \mathrm{Han} \mathrm{Y}$, et al. Trichoscopic findings of androgenetic alopecia and their association with disease severity. J Dermatol 2015;42(6):602-7.

[3] Inui S, Nakajima T, Itami S. Scalp dermoscopy of androgenetic alopecia in Asian people. J Dermatol 2009;36(2):82-5.

[4] Kibar M, Aktan S, Bilgin M. Scalp dermatoscopic findings in androgenetic alopecia and their relations with disease severity. Ann Dermatol 2014;26(4):47884.

[5] Deloche C, de Lacharriere O, Misciali C, et al. Histological features of peripilar signs associated with androgenetic alopecia. Arch Dermatol Res 2004;295(10):422-8.

[6] Rakowska A, Slowinska M, Kowalska-Oledzka E, et al. Dermoscopy in female androgenic alopecia: method standardization and diagnostic criteria. Int J Trichology 2009;1(2):123-30.

[7] Ross EK, Vincenzi C, Tosti A. Videodermoscopy in the evaluation of hair and scalp disorders. J Am Acad Dermatol 2006;55(5):799-806.

[8] Wadhwa SL, Khopkar U, Nischal KC. Hair and scalp disorders. In: Valia RG, Valia AR. (eds). IADVL textbook of dermatology. $3^{\text {rd }}$ edn. Mumbai: Bhalani Publishing House 2010:1368-72.

[9] Paus R, Oslen EA, Messenger AG. Hair growth disorders. In: Wolff K, Goldsmith LA, Katz SI, et al. (eds). Fitzpatrick's dermatology in general medicine. $7^{\text {th }}$ edn. New York: McGraw Hill 2008:753-77.

[10] Hegde SP, Naveen KN, Athanikar SB, et al. Clinical and dermatoscopic patterns of alopecia areata: a tertiary care centre experience. Int J Trichol 2013;5(3):132-6.

[11] Inui S, Nakajima $\mathrm{T}$, Nakagawa $\mathrm{K}$, et al. Clinical significance of dermoscopy in alopecia areata: analysis of 300 cases. Int J Dermatol 2008;47(7):68893.

[12] Mane M, Nath AK, Thappa DM. Utility of dermoscopy in alopecia areata. Indian J Dermatol 2011;56(4):407-11. 